\title{
Storytelling in different cultural context: Applications to hearing loss public awareness campaign
}

\author{
Vinaya K. C. Manchaiah and Fei Zhao
}

Linköping University Post Print

\section{Tweet}

N.B.: When citing this work, cite the original article.

Original Publication:

Vinaya K. C. Manchaiah and Fei Zhao, Storytelling in different cultural context: Applications to hearing loss public awareness campaign, 2012, Journal of Behavioral Health, (1), 4, 322329.

http://dx.doi.org/10.5455/jbh.20120729114709

Copyright: Scopemed. Under Creative Commons licenses by-nc/3.0/ which permits unrestricted, non-commercial use, distribution and reproduction in any medium, provided the work is properly cited.

http://www.scopemed.org/

Postprint available at: Linköping University Electronic Press

http://urn.kb.se/resolve?urn=urn:nbn:se:liu:diva-78190 


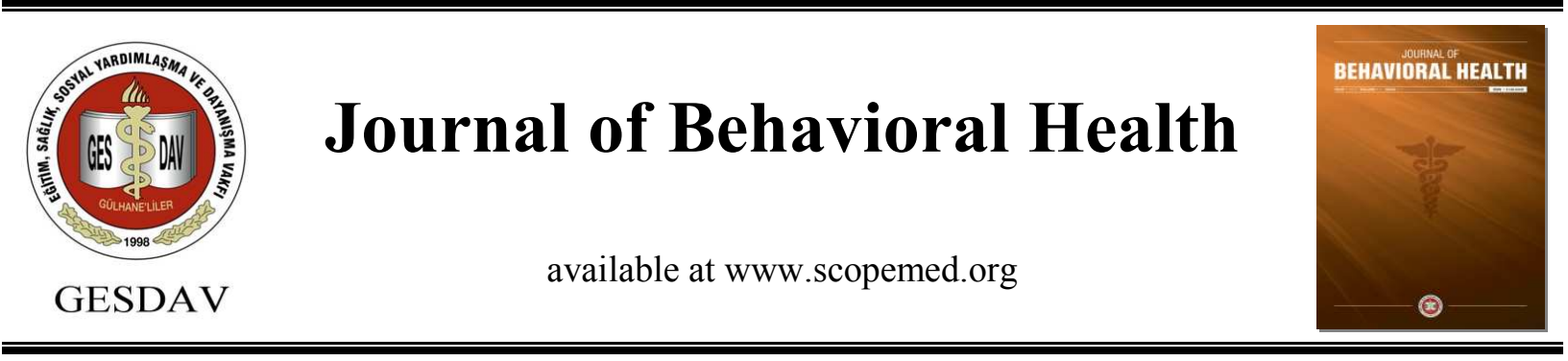

Review Article

\title{
Storytelling in different cultural context: applications to hearing loss public awareness
}

\author{
Vinaya K. C. Manchaiah ${ }^{1,2}$ Fei Zhao $^{3}$ \\ ${ }^{I}$ Centre for Long Term and Chronic Conditions, College of Human and Health Sciences, Swansea University, \\ Swansea SA2 8PP, United Kingdom \\ ${ }^{2}$ Linnaeus Centre HEAD, The Swedish Institute for Disability Research, Department of Behavioral Science and \\ Learning, Linköping University, SE-58183, Linköping, Sweden \\ ${ }^{3}$ Centre for Hearing and Balance Studies, University of Bristol, Bristol BS8 1TN, United Kingdom
}

Received: May 21, 2012

Accepted: July 29, 2012

Published Online: August 02, 2012

DOI: $10.5455 /$ jbh.20120729114709

Corresponding Author:

Vinaya K. C. Manchaiah,

Centre for Long Term and Chronic

Conditions, College of Human and Health

Sciences, Swansea University, Swansea SA2

8PP, United Kingdom

V.K.C.Manchaiah@swansea.ac.uk

\begin{abstract}
Hearing impairment is known to be one of the most frequent sensory impairments. This condition is known to be a hidden disorder which is under recognised and under treated all around the world. The World Health Organisation (WHO) estimates suggest that there are over 275 million people with hearing impairment and $80 \%$ of them living in low and middle income countries. Moreover, the estimates suggest that incidence and prevalence of hearing loss and also the number of people with hearing loss accessing services varies considerably across countries. This rises the need for health promotion (or public awareness campaigns) directed to increase awareness and education of hearing loss and hearing healthcare. This paper provides brief discussion on 'Stories and storytelling', 'Cross-culture and cross-cultural communication' and 'Health promotion and cultural sensitivity'. The central focus of this paper is to highlight the applications of storytelling in different cultural context in health promotion, particularly to hearing loss public awareness campaigns
\end{abstract}

Key words: Storytelling, Cross-culture,

Communication, Public awareness, Health

promotion, Hearing loss, Hearing impairment

(C) 2012 GESDAV

\section{INTRODUCTION}

Hearing impairment is one of the most frequent sensory impairments. The World Health Organisation estimates suggest that there are 275 million people who have moderate to profound hearing impairment throughout the world and $80 \%$ of them living in low and middle income countries [1]. However, it is still known to be a hidden disorder which is under recognised and under treated. Furthermore, it is known to have physical, mental/psychological, social and employment consequences $[2,3]$.

A number of studies have shown that incidence and prevalence of hearing loss and also the number of people with hearing loss accessing hearing healthcare services (e.g., uptake of hearing aids) vary considerably across countries [4-9]. For example, Table 1 provides details of country population, estimated number of people with hearing loss and estimated percentage of people with hearing loss with hearing aids in India, China, United Kingdom (UK) and United States (USA) which show considerable difference. Whilst there are number of reasons for the discrepancies with these figures, one reason could be the variation in the perception of hearing disability across cultures (both within and across the countries). For this reason, these figures can't be compared directly and this may call for the need to better understanding of hearing disability from different cultural perspectives. Furthermore, because hearing loss is not noticed easily which may have hidden implications, and such effects are largely ignored. For this reason effective means of health promotion are necessary. 
Journal of Behavioral Health 2012; 1(4):322-329

Table 1. Country population, estimates of hearing loss and hearing aid uptake in India, China, UK and USA

\begin{tabular}{llll}
\hline Country & Population & $\begin{array}{l}\text { Estimated number of people with } \\
\text { hearing loss }\end{array}$ & $\begin{array}{l}\text { Estimates of \% of people with } \\
\text { hearing loss with hearing aids }\end{array}$ \\
\hline India & 1.2 billion & 63 million & 1 to $2 \%$ \\
\hline China & 1.3 billion & 30 million & 1 to $8 \%$ \\
\hline UK & 62 million & 9 million & 20 to $25 \%$ \\
\hline USA & 311 million & 36 million & $25 \%$ \\
\hline
\end{tabular}

There is strong evidence to suggest that stories can be effective means of education. Stories can be defined in number of ways, but some forms are more used than others in recent years (e.g., digital storytelling). When taking the global perspective to hearing loss public awareness campaigns, we believe there is a need for using effective cross-cultural communication methods. This paper provides brief discussion on the areas 'Stories and storytelling', 'Cross-culture and crosscultural communication' and 'Health promotion and cultural sensitivity'. The central focus of this paper is to highlight the applications of sharing in different cultural context in health promotion, particularly to hearing loss public awareness campaigns. Appendix section provides details of some terminologies used mainly in relation to culture to assist the readers.

\section{STORIES AND STORYTELLING}

Stories can be defined in number of ways. For example, strictly stories must have a beginning, middle and ending which is bit restrictive [10]. However, an open approach could be that "stories discipline by defining characters, sequencing plots, and scripting actions. Moreover, stories precede people's birth and linger after their death, which may involve oral or written performance involving two or more people interpreting past or anticipated experience" [11]. In general, stories are a series of events which have been used as a means conveying information, education, entertainment, building communities, promote innovation, preserving cultural values and to instil moral values for many centuries. Furthermore, stories have been used to give meaning to life, express values and convey culture; to connection of one's own self, experience and life; to connect individual and groups (and also other cultures) based on their past; to give one a sense of wholeness (i.e., small pieces of information fit together to add up as something). Great teachers and leaders have used stories as instructional means to convey important instructions in the form of parables, legends, myths, fables and real-life examples $[12,13]$.
Storytelling is known to be the second oldest profession in the world. Stories are told to 'enact' an account of themselves and the community [14]. Stories can be told in numerous ways, some examples may include: (1) oral narration; (2) singing; (3) art - which involves creating a beauty; (4) games - which involve rules and competition; (5) play - which involves collaborative act of performance; (6) writings - articles, chapters, books; (7) video clips - short clips, documentaries, movies; (8) digital stories - various creative ways using digital media. Whilst stories can be told in number of ways, with the advancements in technology digital storytelling has become a powerful instructional tool in the recent years [15]. In addition, the more imaginative and interactive ways of storytelling can be adopted using digital methods $[16,17]$. Furthermore, because of the adaptive nature digital storytelling can be used as an effective means of cross-cultural communication.

Stories have contributed significantly for learning in all cultures, especially mythological stories which have four main functions: mystical, cosmological, sociological and pedagogical [18]. From a cultural perspective, research suggests that myths from different culture seem to have similar structure that revolves around a hero, because the stories are metaphor for life $[19,20]$. Moreover, in some culture without the written language stories were the only way to convey society's culture [21]. In addition, same or similar stories such as classical myths and heroic legends are retold in another time and culture to meet different audience [22].

Stories are known to be one of the most efficient ways or organising information and there are number of advantages of storytelling in learning. The most important aspects of stories are that they have emotional aspect and because of the coherent temporal progression of events they are easy to remember [23]. Moreover, cognitive psychology literature suggests that stories provide contextually rich learning experience by activating strategies such as guiding attention, encouraging elaborative encoding, facilitating knowledge organisation, encouraging self-reliance and 
inspiring emotions [24]. It is believed that these strategies tap into human information processing mechanisms. Overall, by considering wide range of literature from history, culture studies, cognitive psychology, and organisational studies and also by considering using the anecdotal reports it can be concluded that stories are a simple and powerful way of reaching people. However, authentic stories which are told by people usually needs to be interpreted in the cultural context. For this reason, cross-cultural considerations are necessary to convey the meaning of the stories effectively.

\section{CROSS-CULTURE AND CROSS-CULTURAL COMMUNICATION}

\section{Perspective on Cross-culture}

The concept of culture has various inter-related meanings. In general, the term 'culture' is used in three main contexts, which include: (1) high culture excellence in taste in fine arts; (2) set of shared values, attitudes, and goals which constitutes a group; and (3) patterns of human knowledge, belief and behaviour which are acquired through social learning. In this manuscript, the 'national culture' has been used in the arguments which mainly relate to later two meanings presented above.

If we consider cultures as a social construct, it is almost impossible to have an universal scale to measure and understand cross-cultural differences. There are hundreds and thousands of national and regional cultures; however, they can be roughly classified into groups [25] and the similarities and differences can be studied. An international study by Hofstede [26] identified four main cross-cultural dimensions of national culture, which include: Power Distance (PD), Individualism versus Collectivism (IDV), Masculinity versus Femininity (MAS), and Uncertainty Avoidance (UAI). In 1991 a fifth dimension 'Long-term Orientation (LTO)' was added and more recently, a sixth dimension 'Indulgence versus Restraint' has been added [27]. Figure 1 shows the cross-cultural differences in India, China, UK, and USA within these five dimensions.

Whilst there are number of critics to these five dimensions, mainly because they were developed by analysing large data on employee core values of IBM in the work context and may not be directly transferable to other contexts, it may be used as the starting point in understanding the cross-cultural differences. For example, from Figure 1 it is clear that in the dimensions PD, IDV and LTO there is considerable difference across these countries. It can be said that people in China and India have more power distance, more long-term orientation and also collective culture when compared to UK and USA. As a starting point, this may suggest that stories which address collectivism and the long-orientation aspects may be more effective in reaching people in India and China.

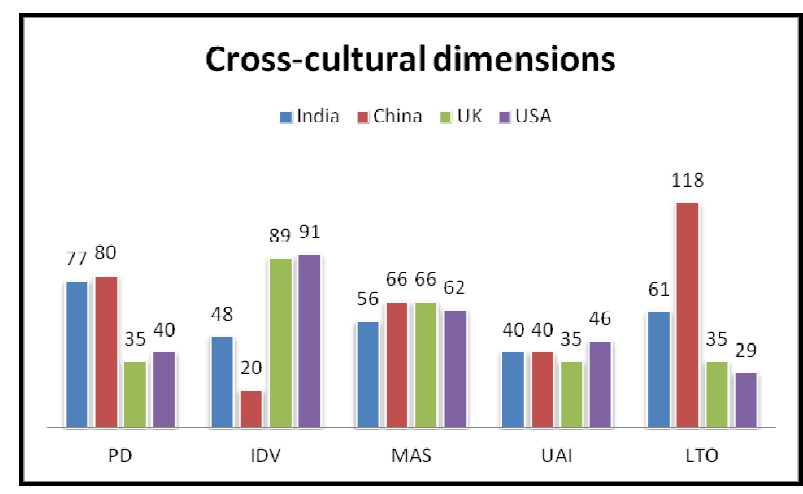

Figure 1. Cross-cultural dimensions of India, China, UK and USA

Much about cross-cultural difference can be learnt from studies on marketing and organisational behaviours. Gesteland [28] identified various patterns of crosscultural business behaviour which include: Dealfocused (DF) versus Relationship-focused (RF) cultures; Informal versus formal cultures; Rigid-time versus fluid-time cultures; Expressive versus reserve cultures. He argued that businesses tend to have either DF or RF cultures which may have significant impact on bushiness behaviour in the marketplace, particularly in the way they communicate. For example, DF cultures use more direct, frank and straightforward language, while RF cultures prefer indirect, subtle, roundabout style conversation while negotiations. In addition, studies on international marketing have identified the importance of cultural differences in relation to consumer values, needs and buying behaviour in effective implementation of international marketing methods [29]. The above discussion may provide some insights into cross-cultural perspectives.

\section{Cross-cultural Communication}

Cross-cultural communication refers to how individuals influenced by different cultural communities negotiate shared meanings in interaction [30]. Cross-cultural communications and intercultural communications have sometime been used synonymously in the literature. However, the difference is that cross-cultural communication involves comparison of communication across cultures and intercultural communication involves communication between people from different cultures [31]. Whilst in this manuscript we refer crosscultural communications for communications among individuals from different nations, this term has been used in literature to refer to inter-ethnic, inter-religious and inter-regional communication. 
Lewis argued that there are considerable cross-cultural differences in verbal communication especially in terms of communication behaviour, listening habits, audience expectations [32]. In addition, the difference can also be seen in other aspects such as leadership styles and language of management which may influence the verbal communication. However, in each national culture the communication behaviour, listening habits and the manipulation behaviours are surprisingly consistent. For example, when the word is spoken the actual meaning of the message emerges only when it is considered in context, but when they are recognised by an outsider the pattern becomes predictable. Interestingly, Lewis [32] has used visual approach to present these cross-cultural differences in communication, which suggest that use of non-verbal communication could be effective. In addition, there could be difference in communication styles [33]. For example, explicit versus implicit communication, direct versus indirect communication, use of praise, use of silence, and some language considerations.

One of the barriers to cross-cultural communication is 'cultural noise' which refers to obstructions to successful communication between people of different cultures [34]. The sources of cultural noise may include differences in language (e.g., same words with different meanings), differences in values, non-verbal cues (e.g., interpretation of body language), channel or medical of chosen communication (i.e., familiarity or preferences to particular medium of communication) and various other factors. For this reason, it is important to be aware of any such barriers which may affect the message from being interpreted (or perceived) in the way the sender intended. It is important to have special understanding of the communication process and the various sources of cultural noise which may hinder the communication process to establish effective crosscultural communication.

Globalisation has major implications to cross-cultural communications [35]. This is because globalisation has provided new target group, professional practitioners in multiethnic societies and it has made 'cultural identity' one of the most important aspects of intercultural research. In addition, globalisation has resulted in contamination, increased cultural pluralism and hybridization of national culture [36]. Whilst it may be hard to clearly define communications within each national culture, the broad categories of differences, similarities and preferences can be obtained within nation culture in the context of continuum of 'interculturelness' [37]. This discussion highlights the fact that the same information (story or a narrative) has to be modified to meet different cultural contexts. Therefore it is crucial to consider cross-cultural communication to enable effective communications with audience with specific cultural background.

\section{HEALTH PROMOTION AND CULTURAL SENSITIVITY}

Health promotion refers to "the process of enabling people to increase control over their health and its determinants, and thereby improve their health" [38]. Key aspects of effective health promotion is to consider step-by-step planning in terms of clear and realistic objectives, target population, information presented in the context to make it meaningful, implementation, and appropriate evaluation methods. It has been well known that social and psychological factors such as people's attitudes and behaviour towards health and illness, cultural values, and social support, play an important role in people's health consciousness and disease prevention process [39]. Moreover, primary means of health promotion occurs by addressing such social and psychological factors with an emphasis to change behavioral risk factors. In recent decades there has been considerable increase in people's health conscious which may be due to increase and improvements to health promotion activities.

It is believed that culture is an extremely important factor which health educators needs to consider as culture shapes perception and practices in relation to health, illness, and medicine and mediates responses to health education information [40]. Even though there could be a number of cross-cultural differences to health consciousness, in general, all countries share a desire to improve the health of their citizens, to monitor the improvements they make and to make further adjustments to their life-style to further improve the effectiveness of health [39]. However, there could be some barriers to cross-cultural health promotions (refer to Table 2). One of the important aspects of crosscultural health promotion is to make considerations for 'cultural sensitivity' which refers to quality of being aware and accepting of other cultures [41-43]. For example, what may be considered as normal or acceptable in some cultures can be considered as rude or derogatory in others. Cultural sensitivity in health planning, communication and intervention is vital in building a meaningful connection [43]. Moreover, it is important to address domains of cultural sensitivity in relation to health problems and health promotions.

There appears to be multiplicity and/or pluralism in the concept of cultural sensitivity. Resnicow et al. [41] describes cultural sensitivity in relation to health promotion in two dimensions, which include: (1) surface structure - matching intervention materials and messages to observable or superficial characteristics of the target population (i.e., aspects such as people, places, language, product brands, music, food etc and 
how well interventions fit within a specific culture); (2) deep structure - involves incorporating cultural, social, historical, environmental, and psychological factors that influences the target health behaviour in the target population (e.g., peer influence exerting greater influence on substance use). Kline suggested that achieving cultural sensitivity in health promotion materials necessitates attention to slight differences in meanings in messages, revision of questionable arguments and evidences, and avoidance of ambiguity (i.e., cultural noise) [42].

Table 2. Some key aspects which may act as barriers to crosscultural health promotions

- Differences in the education and knowledge of disability

- Differences in attitudes, perception and management of disability

- Differences in incidence and prevalence of health conditions

- Difference in risk factors

- Financial barriers

- Barriers in terms of infrastructure (i.e., health related)

- Level of readiness to identification and management of health condition

- Expectations on aspects related to quality of life

This discussion may highlight the fact that there is no single approach which may suite all cultures and communities. Even though the health promotion goals and message could be the same (e.g., increasing awareness, changing behaviour), there is a clear need for targeted and tailored promotional materials considering cross-cultural communication aspects in order for it to be effective.

\section{[Hearing Loss Awareness Campaigns]}

Although hearing impairment is one of the most frequent chronic conditions, up to half of all such cases are avoidable through primary prevention and a large percentage can be treated through early diagnosis and suitable management [1]. There is a clear need for public health policies to address hearing loss, early intervention, and improved hearing loss prevention and hearing conservation practices [44-46]. Furthermore, one important aspect of hearing loss awareness campaigns is to develop and apply them in a specific context of the population. A typical example of such segmentation is based on type of disorder to capture different population such as childhood hearing impairment, age-related hearing loss and noise/music induced hearing loss.

Whilst there are various methods which can be used for hearing loss awareness, we believe authentic stories could be very effective. The use of hearing loss success stories can be noticed frequently in various websites, newsletters and other communication of various charities, organisations and hearing loss support groups to effectively promote hearing health. However, there has been no literature indicating the applications of storytelling in hearing loss awareness campaigns.

Story and narrative mean the same thing. However, the term 'narrative' has been mainly used in academic writing and the narrative approach has been extensively used in disability research to study and understand the lived experiences of person with disability and their family members [47]. Manchaiah and Stephens used narrative approach to illustrate the patient journey (i.e., experience and millstones) of a person with hearing impairment [48]. They argued that it can help highlight the individuality and uniqueness of each person facing the same challenge and also helpful to illustrate the complexity of the psychosocial aspects of acquired hearing impairment. In addition, exposures hearing loss narratives are effective in increasing the affective elements in undergraduate students' technical and informational responses [49]. A recent international study which looked into perspectives of adults with hearing impairment suggested that people largely describe hearing help-seeking and rehabilitation in the context of their daily life [50]. This may suggest that using stories/narratives in the context of daily life may be more appropriate way to reach people rather than using facts and figures related to medical explanations.

Whilst the stories can be told in number of ways, in the recent years there is an increase in the use of digital storytelling methods as instructional tools. Furthermore, imaginative and interactive ways of storytelling can be adopted using digital storytelling methods. The digital story telling methods may include various formats including web-based stories, interactive stories, hypertexts, and narrative computer games. However, short stories of 2 to 3 minute made as multimedia movies that combine photographs, video, animation, sound, music, text, and often a narrative seem to be very effective. Examples of such an approach can be seen in the websites of the Centre for Digital Storytelling (http://www.storycenter.org/), Silence Speaks (http://www.silencespeaks.org/), and Swansea Digital Storytelling (http://swanseastorytelling.com/).

The perception of the disability can be significantly 
influenced by the culture. To highlight this some examples from anecdotal notes were drawn as follows: (1) a person with hearing loss in Palestine refused tow are hearing aids. This is because he reported that currently his grand children are always with him to help interpret the missing information from conversations and he felt using hearing aids may compromise his contact with his grandchildren; and (2) a person with hearing loss in South-India reported that his hearing difficulties were never really a social problem when he was at home as most people at home and in his social circle would speak quite loud. However, he faced difficulties when he travelled abroad where he encountered various soft-spoken people. These examples may to some extent highlight the deep layers of how the perception of hearing loss as a disability and the help-seeking behaviour may be influenced by culture. For this reason, considering cross-cultural difference in communications and perception of hearing loss as a disability it would make sense to use the stories in the cultural context. Moreover, the hearing loss awareness campaigning materials needs to be prepared accounting for cultural sensitivity, which would help in reducing cultural noise in communication and to preserve cultural identity. Whilst the storytelling could be a theme, its implementations in health promotions, particularly hearing loss awareness needs to be thought through more carefully (e.g., ways to collect authentic stories from people with hearing loss and means of communicating this to wider audience).

\section{CONCLUSIONS}

Stories are known to be a simple and powerful way of conveying complex information and have number of advantages in communication, education and awareness. This is because of the rich contextual learning and emotional experience they produce. Stories have been used a means of education and inspiration in number of settings as instructional methods in universities, to convey the culture in organisations, to inspire people in leadership training mainly in army, and so on. Considering a wide range of cross-cultural perspectives and barriers to crosscultural communications, it is important to present the stories in different cultural context. The storytelling approach, especially digital storytelling could be used as a means of cross-cultural communications. Moreover, in relation to hearing loss awareness campaigning materials need to be prepared accounting for cultural sensitivity, which would help in reducing cultural noise in communication and to preserve cultural identity. Overall, both theoretical and practical arguments suggest that storytelling in different cultural context could be an effective means of health promotion in particular to hearing loss public awareness campaigns.

\section{ACKNOWLEDGEMENTS}

The inspiration for this paper comes from developing an idea for the global hearing loss awareness competition 'IDEAS' facilitated by Ida Institute and funded by the Oticon Foundation, Denmark. The idea of 'Sharing stories in different cultural context: Hearing loss awareness' was awarded the idea of the month April 2012 based on most public votes.

\section{REFERENCES}

1. World Health Organization. 2005. Deafness and hearing impairment, Fact Sheet No. 300. http://www.who.int/mediacentre/factsheets/fs300/en/ [Access date: May 21, 2012].

2. Barlow JH, Turner AP, Hammond CL, Gailey L. Living with late deafness: Insight from between worlds. International Journal of Audiology. 2007; 46(8): 442-448.

3. Chia E-M, Wang JJ, Rochtchina E, Cumming RR, Newall P, Paul, M. Hearing impairment and health-related quality of life: The Blue Mountains hearing study. Ear and Hearing. 2007; 28: 187-195.

4. McPherson B, Brouillette R. Audiology in developing countries. Nova Science Pub Inc.; 2008.

5. Chu HM. Hearing loss in older Chinese: the Guangzhou Biobank Cohort Study. Hong Kong: University of Hong Kong; 2006.

6. NSSO. Disabled persons in India. NSS 58th round. National Sample Survey Organisation, New Delhi. JulyDecember 2002.

7. Stephens D, Lewis P, Davis A, Gianopoulos I. Vetter N. Hearing aid possession in the population: lessons from a small country. Audiology 2001; 40: 104-111.

8. Meredith R, Manchaiah VKC, Stephens D. Estimating NHS Hearing Aid Uptake in Wales Using AuditBase. BSA News. 2011; 62: 17-21.

9. Kochkin S. MarkeTrak VIII: 25-year trends in the hearing health market. The Hearing Review. 2009; 16: $12-31$.

10. Bruner J. Acts of meaning. Cambridge, MA: Harvard University Press; 1990.

11. Boje, D. The storytelling organization: A study of storytelling performance in an office supply firm. Administrative Science Quarterly. 1991; 36: 106-126

12. Brown JS, Duguid P. Organizing knowledge. California Management Review. 1998; 40(3): 90-111.

13. Davenport TH, Prusak L. Working knowledge: How organizations manage what they know. Boston, MA: Harvard Business School Press; 1998.

14. Browning LD. Organizational narratives and 
organizational structure. Journal of Organizational Change Management. 1991; 4(3): 59-67.

15. Robin, B.R. Digital Storytelling: A powerful technology tool for the $21^{\text {st }}$ century classroom. Theory into Practice. 2008; 47: 220-228.

16. Louchart S, Aylett, R. Narrative theory and emergent interactive narrative. International Journal of Continuing Engineering Education and Lifelong Learning. 2004; 14(6): 506-518.

17. McDonald JK. Imaginative instructions: what master storytellers can teach instructional designers. Educational Media International. 2009; 46(2): 111-122.

18. Campbell J. The hero's journey. Novato, CA: New World Library; 1990.

19. Campbell J, Moyers W. The power of myth. New York, NY: Doubleday, 1991.

20. Campbell J. The hero with a thousand faces. 3rd edition. Novato, CA: New World Library; 2008.

21. Andrews DH. Story types and the hero story. In D. Andrews, T. Hull, \& K. DeMeester (Ed.) Storytelling as Instruction. Boston: Sense Publishers; 2010.

22. Stephens J, McCallum R. Retelling stories, framing culture: traditional story and metanarratives in children's literature. USA: Routledge; 1998.

23. Ochs E, Capps L. Living Narrative: Creating lives in everyday storytelling. London: Harvard University Press; 2001

24. Branaghan RJ. What's so special about stories? The cognitive basis of contextually rich learning. In D. Andrews, T. Hull, K. DeMeester (Ed.) Storytelling as Instruction. Boston: Sense Publishers; 2010.

25. Lewis RD. When cultures collide: Leading across cultures. Boston: Nicholas Brealey Publishing; 2006.

26. Hofstede G. Culture's Consequences: International Differences in Work-Related Values. Beverly Hills, CA: Sage Publications, 1980.

27. Hofstede G, Hofstede GJ, Minkov M. Cultures and Organizations: Software of the Mind: Intercultural Cooperation and Its Importance for Survival. $3^{\text {rd }}$ edition. USA: The McGraw-Hill Companies; 2010.

28. Gesteland RR. Cross-cultural business behaviour: Marketing, negotiating, sourcing, and managing across cultures. Copenhagen: Copenhagen Business Press; 2002.

29. Kim J, Forsythe S, Gu QL. Cross-cultural consumer values, needs and purchase behaviour. Consumer Marketing. 2002; 19(6): 481-503.

30. Ting-Toomey S. Communicating across cultures. New York: The Guilford Press; 1999.

31. Gudykunst BW. Cross-cultural and intercultural communications. London: Sage Publications, Inc.; 2003.

32. Lewis RD. Cross cultural communications: A visual approach. Hampshire: Transcreen Publications; 1999.
33. Thomas DC. Cross-cultural management. $2^{\text {nd }}$ edition. California: Sage Publications, Inc; 2008.

34. O'Connell J. Cultural Noise. In J. McNett, H.W. Lane, M.L. Maznevski, M.E. Mendenhall, J. O'Connell. (Eds). The Blackwell Encyclopedia of Management: Volune VI: International Management. Wiley-Blackwell; 2006.

35. Jensen I. The Practice of Intercultural Communication: reflections for professionals in cultural encounters. In Titley, G. (Ed.), Resituating culture. Strassbourg: Council of Europe; 2004. P. 81-92.

36. Craig CS, Douglas SP. Beyond national culture: implications of cultural dynamics for consumer research. International Marketing Review. 2006;23(3):322-342.

37. Gudykunst WB, Kim YY. Communication with strangers. $3^{\text {rd }}$ edition. Boston: McGraw Hill, 2003.

38. World Health Organization. 2005. The Bangkok Charter for health promotion in a globalized world. 6th Global Conference on Health Promotion. Geneva, Switzerland: World Health Organization. http://www.who.int/healthpromotion/conferences/6gchp/h pr_050829_\%20BCHP.pdf [Access date: May 21, 2012].

39. Conner RF. A cross-cultural assessment of health promotion/disease prevention programs. Evaluation and Program Planning. 1988; 11: 179-187.

40. Guidry JJ, Fagan P, Walker V. Cultural sensitivity and readability of breast and prostate printed cancer education materials targeting African Americans. Journal of the National Medical Association. 1998; 90: 165-169.

41. Resnicow K, Soler R, Braithwaite RL, Ahluwalia JS, Butler J. Cultural sensitivity in substance use prevention. Journal of Community Psychology. 2000; 28(3): 271-290.

42. Kline KN. Cultural sensitivity and health promotion: Assessing breast cancer education pamphlets designed for African American women. Health Communication. 2007; 21(1): 85-96.

43. Hess J.E. Culturally sensitive health promotion for tuberculosis prevention and treatment in Mexican migrant farm worker populations. Online Journal of Rural Nursing and Health Care. 2009; 9(2): 95-102.

44. World Health Organization. Strategies for prevention of deafness and hearing impairment. Prevention of noiseinduced hearing loss. Geneva: WHO; 1997.

45. Fausti SA, Wilmington DJ, Helt PV, Helt WJ, KonradMartin D. Hearing health and care: The need for improved hearing loss prevention and hearing conservation practices. Journal of Rehabilitation Research and Development. 2005; 42(4): 45-62.

46. Meinke DK, Morata C. Awarding and promoting excellence in hearing loss prevention. International Journal of Audiology. 2012; 51: S63-70.

47. Valeras AB. We don't have a box: Understanding hidden disability identity utilizing narrative research methodology. Disability Studies Quarterly. 2010; 30(3/4). http://dsq-sds.org/article/view/1267 [Access date: may 21st 2012]. 
48. Manchaiah VKC, Stephens D. The Patient Journey: Living with hearing impairment. Journal of the Academy of Rehabilitative Audiology. 2011; 44: 29-40.

49. Berg AL, Canellas M, Salbod S, Velayo R. Exposure to disability and hearing loss narratives in undergraduate audiology curriculum. American Journal of Audiology. 2008; 17(2): 123-128.

\section{Appendix: Terminologies}

\begin{tabular}{|c|c|}
\hline Power Distance (PD) & $\begin{array}{l}\text { The degree to which the less powerful members of a society accept and expect that power is } \\
\text { distributed unequally and how a society handles inequalities among people. }\end{array}$ \\
\hline $\begin{array}{l}\text { Individualism versus } \\
\text { Collectivism (IDV) }\end{array}$ & $\begin{array}{l}\text { Individualism is referred to loosely-knit social framework and collectivism represents a } \\
\text { preference for a tightly-knit framework. In generally, this refers to extent to which society values } \\
\text { individual or collective achievement. }\end{array}$ \\
\hline $\begin{array}{l}\text { Masculinity versus } \\
\text { Femininity (MAS) }\end{array}$ & $\begin{array}{l}\text { Preference in society for achievement in traditional masculine methods such as heroism, } \\
\text { assertiveness and material reward for success when compared to its opposite, femininity which } \\
\text { may constitute stands for a preference for cooperation, modesty, caring for the weak and } \\
\text { quality of life. }\end{array}$ \\
\hline Uncertainty Avoidance (UAI) & The extent which people in the society tolerate uncertainty or ambiguity \\
\hline Long-term Orientation (LTO) & $\begin{array}{l}\text { The LTO can be interpreted as dealing with society's search for virtue and the extent to which } \\
\text { society focuses on long0term goals and tradition }\end{array}$ \\
\hline Indulgence versus Restraint & $\begin{array}{l}\text { Indulgence stands for a society that allows relatively free gratification of basic and natural } \\
\text { human drives related to enjoying life and having fun. Restraint stands for a society that } \\
\text { suppresses gratification of needs and regulates it by means of strict social norms }\end{array}$ \\
\hline National culture & Shared values, beliefs, attitudes, and pride associated with nation \\
\hline Cultural sensitivity & $\begin{array}{l}\text { The extent to which cultural characteristics, experiences, norms, values, behavioural patterns, } \\
\text { and beliefs of a target population as well as relevant historical, environmental, and social } \\
\text { forces are incorporated in the design, delivery and evaluation of targeted promotion materials } \\
\text { and programmes (Resnicow et al., 2000) }\end{array}$ \\
\hline $\begin{array}{l}\text { Relationship-focused (RF) } \\
\text { culture }\end{array}$ & People in a particular culture predominantly people-oriented \\
\hline Deal-focused (DF) culture & People in a particular culture predominantly task-oriented" \\
\hline Cultural Identity & $\begin{array}{l}\text { Social identity that is based on specific cultural configuration of a conscious nature (i.e., } \\
\text { socially constructed realities) }\end{array}$ \\
\hline
\end{tabular}

This is an open access article licensed under the terms of the Creative Commons Attribution Non-Commercial License which permits unrestricted, non-commercial use, distribution and reproduction in any medium, provided the work is properly cited. 